Patients with acromegaly have increased risk of developing tumors of the gastrointestinal tract. There are some data that IRI, IGF-1BP3, folic acid and vitamin D may influence the development of these tumors.

Aim: To study the influence of IRI, IGF-1BP3, folic acid, vitamin D, CA 19-9, CA 72-4 in the development of tumors of the gastrointestinal tract, and the frequency of neoplasms detection.

Materials and Methods: The study included 120 patients with acromegaly. All patients underwent gastroscopy and colonoscopy with biopsy of revealed tumors. The levels of neoplasms also were studied in all cases.

\title{
Histological examination
}

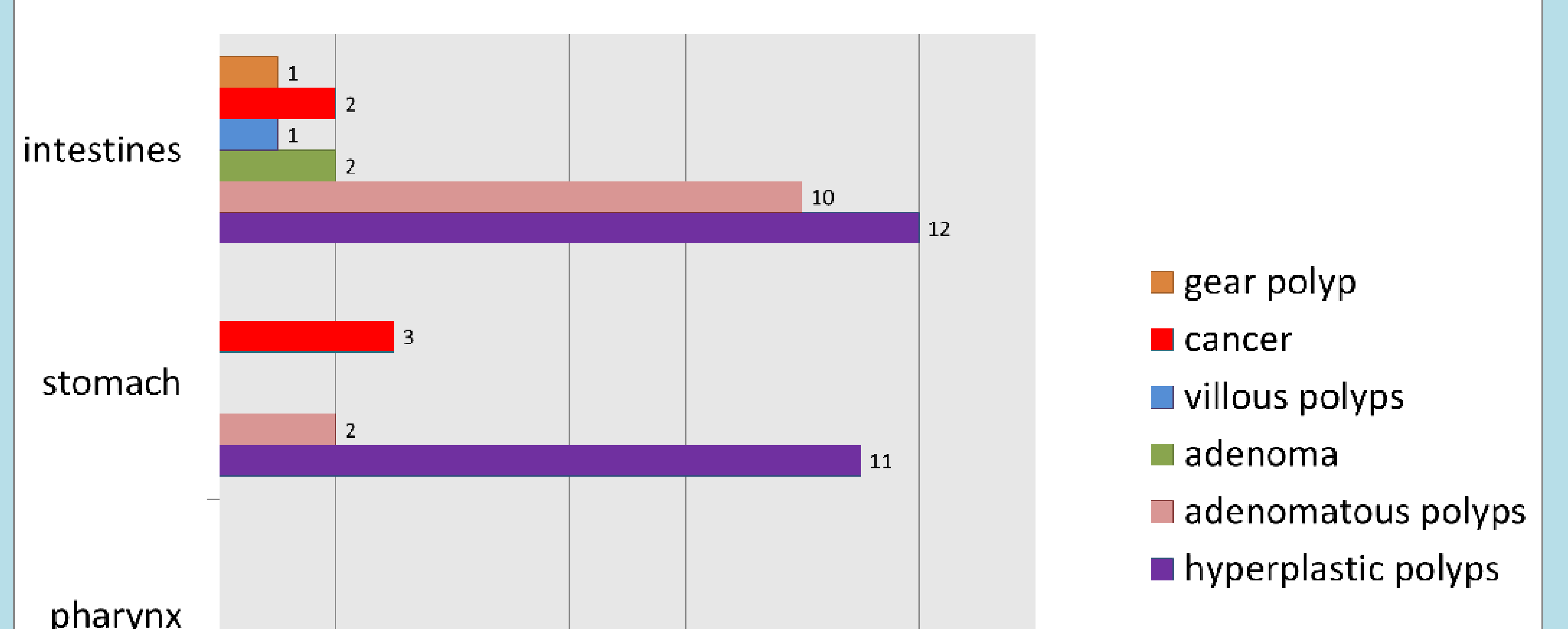

1
Neoplasms were found in 43 patients (35.8\%). Histologically hyperplastic and adenomatous polyps (24/12), 2 patients had villous and tubulovesicular adenoma, gear polyp was found in 1 case, and 5 patients had cancer of stomach and colon. Thus, the frequency of malignant tumors was $4.2 \%$.

\section{ROC-analysis and Binary Logistic Regression}

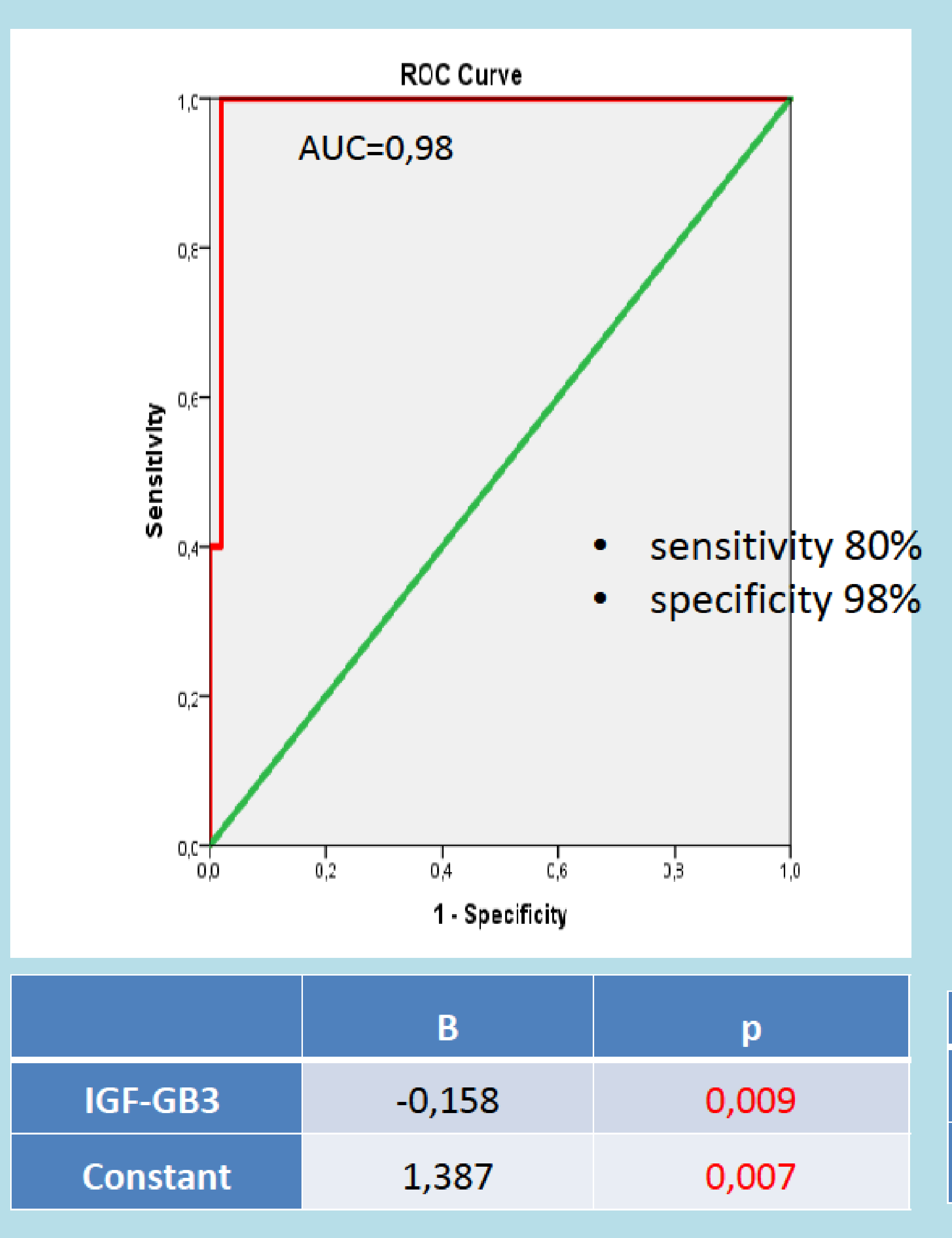

The level of IGF-1BP3 $\geq 3510 \mathrm{mg} / \mathrm{ml}$ was also significantly increased the risk of malignancy

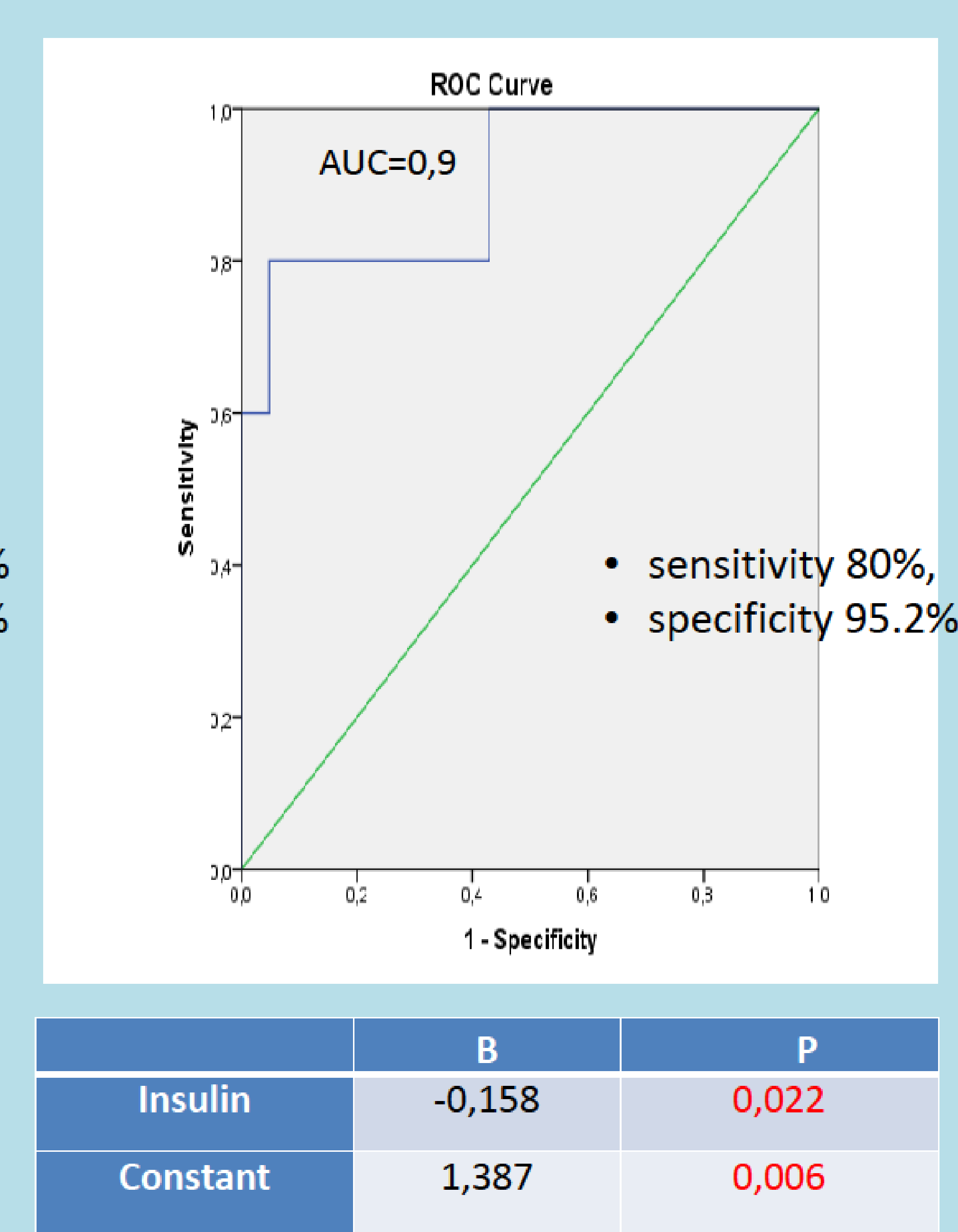

The level of IRI more than 30,1 $\mathrm{mU} / \mathrm{ml}$ and diagnosed neoplasm significantly increased risk of malignancy

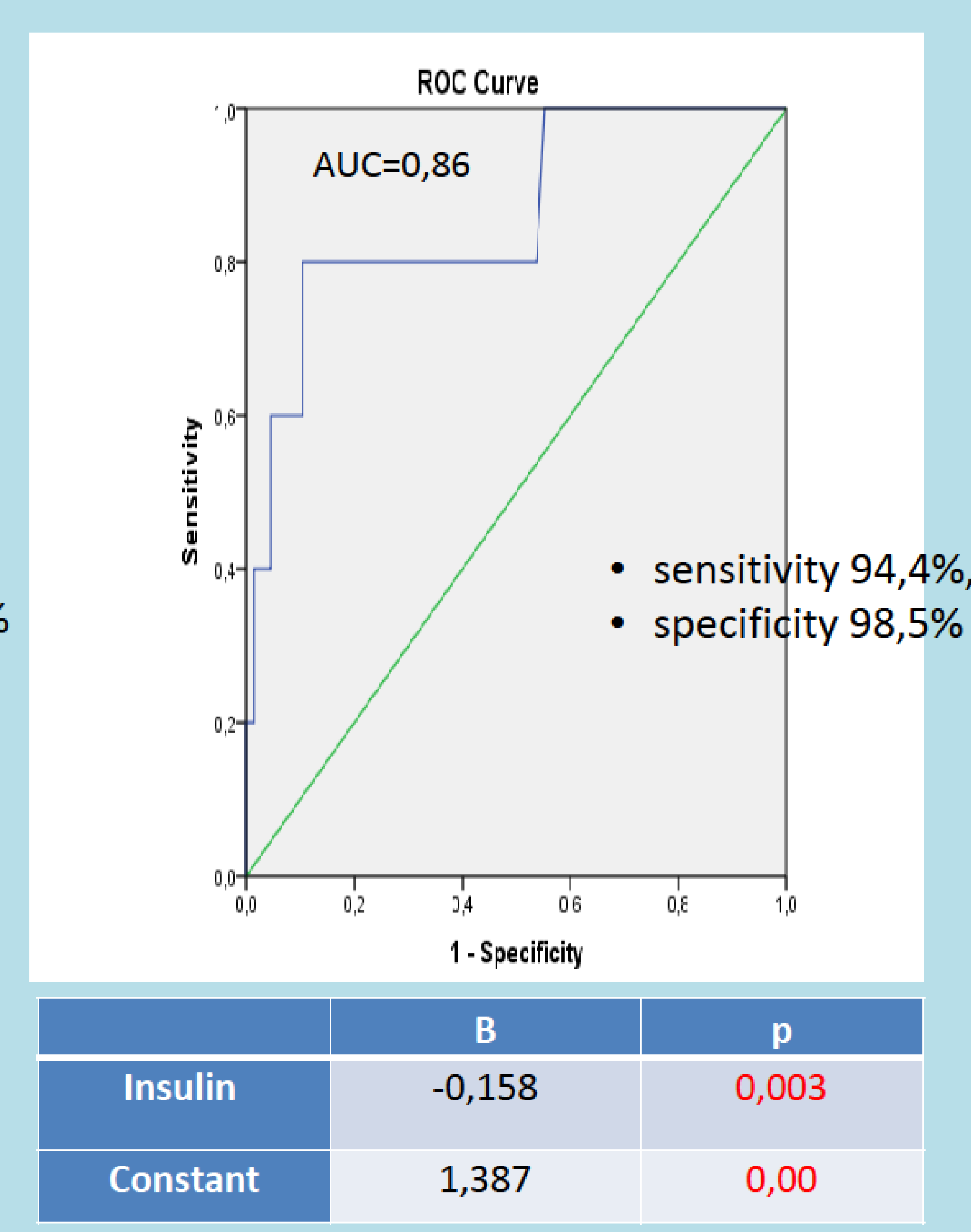

Insulin levels higher than $48,6 \mathrm{mU} / \mathrm{ml}$ lead to significantly increased risk of developing tumors.

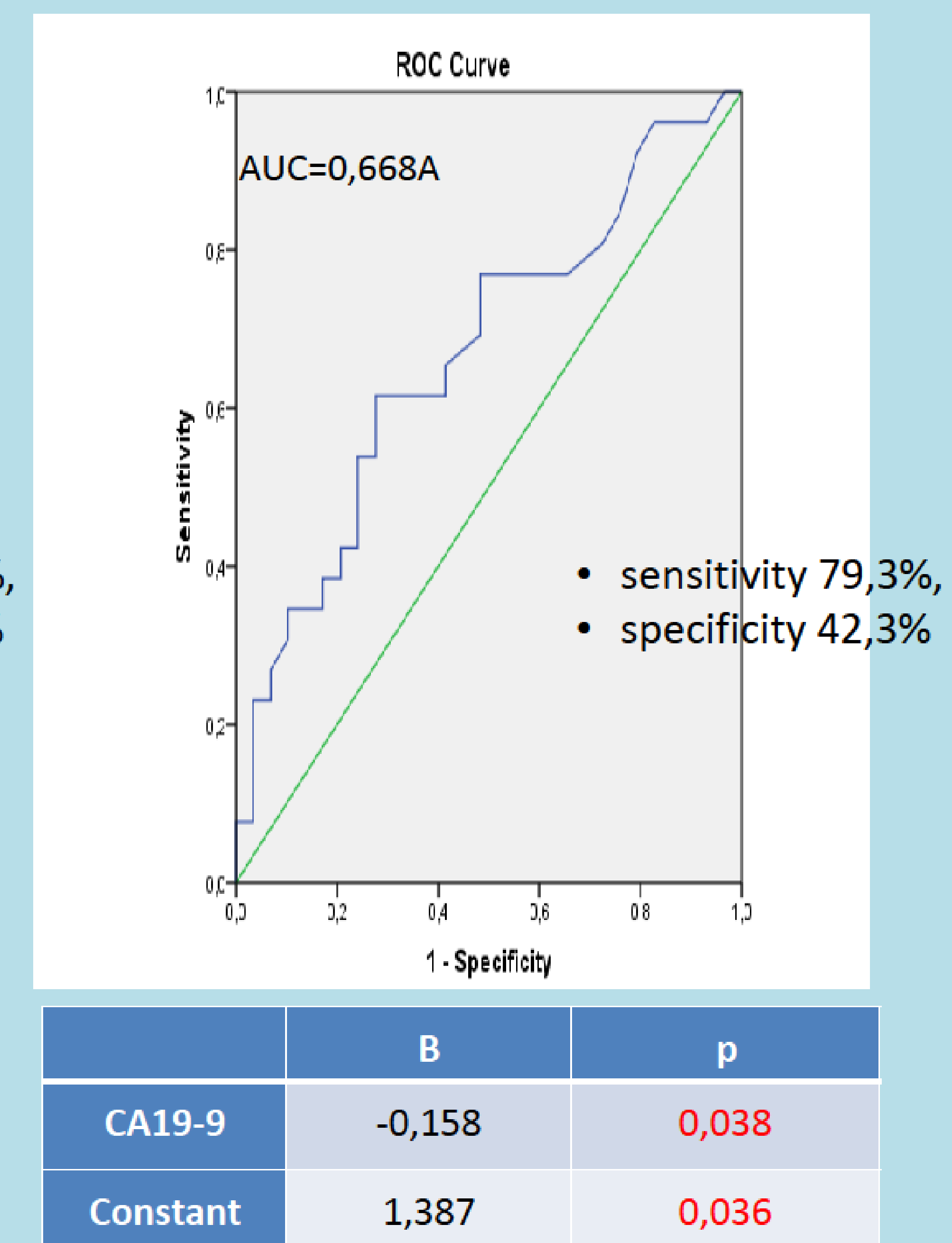

The level of $\mathrm{CA}-19-9 \leq 8,8 \mathrm{U} / \mathrm{L}$ also increased the risk of tumors of the gastrointestinal tract in patients with acromegaly

Patients with tumors and without them were comparable by CA 72-4, folic acid and vitamin D levels.

Conclusions: Patients with acromegaly have the increased risk of neoplasms formation, including malignant tumors. Levels of IRI, IGF-1BP3 and CA 19-9 can be used as the diagnostic criteria of tumors of the gastrointestinal tract in patients with acromegaly. 